\title{
Öğrencilerin Işık Konusundaki Bağlam Temelli Sorular ile Geleneksel Soruları Cevaplama Düzeylerinin Cinsiyete Göre Karşılaştırılması *
}

\section{Merve SAK ${ }^{* *}$, Derya KALTAKÇI GÜREL ${ }^{* * * *}$}

Öz: Bu nedensel karşılaştırmalı araştırma çalışmasında, ortaokul 6., 7. ve 8. sınıf öğrencilerinin 1şık konusundaki bağlam temelli sorular ve geleneksel soruları çözebilme düzeylerinin cinsiyete göre karşılaştırılması amaçlanmıştır. Bu nedenle 6., 7. ve 8. sınıf kazanımlarına uygun olarak her sınıf seviyesi için Işık Başarı Testleri (IBT) geliştirilmiştir. IBT’ler 10 bağlam temelli soru (BTS) ve BTS'lere kazanım ve bilişsel düzey olarak denk 10 geleneksel soru olmak üzere 20 çoktan seçmeli sorudan oluşmaktadır. Uygulama, Kocaeli’nin İzmit ilçesinde 869 öğrenciyle (431 kı ve 438 erkek) gerçekleştirilmiş ve veriler SPSS 23.0 programı kullanılarak MANCOVA testi ile analiz edilmiştir. 6. sınıf için IBT Cronbach alfa güvenirlik katsayısı 0.794, 7. sınıf IBT için 0.785, 8. sınıf IBT için 0.824 olarak bulunmuştur. MANCOVA testi sonuçlarına göre 6. sinıf(Wilks’ $\lambda=0.987, F(2,290)=1.966, p=0.142), 7$. sinıf (Wilks' $\lambda=0.991, F(2,278)=1.257, p=0.286$ ) ve 8 . sinif seviyelerinde (Wilks' $\lambda=0.995$, $F(2,288)=0.732, p=0.482)$ IBT toplam puan, BTS puan ve geleneksel soru puanlarında kız ve erkek öğrenciler arasında anlamlı bir fark bulunamamıştır. Elde edilen bulgular yorumlanarak öğretmenlere, araştırmacılara, müfredat geliştiricilere ve ilgili kurumlara çeşitli önerilerde bulunulmuştur.

Anahtar Kelimeler: Fen eğitimi, bağlam temelli sorular, cinsiyet, 1şık.

\footnotetext{
*Bu makale, birinci yazarın yüksek lisans tezinin bir kısmından türetilmiştir. Ayrıca çalışmanın bir bölümü 33 . Uluslararası Fizik Kongresi’nde sözlü bildiri olarak sunulmuştur.

**Yüksek lisans öğrencisi, Kocaeli Üniversitesi, Matematik ve Fen Bilimleri Eğitimi Anabilim Dalı, ORCID ID: 0000-0002-6003-4056, E-posta: merve.sak05@gmail.com

***Dr. Öğr. Üyesi, Kocaeli Üniversitesi, Eğitim Fakültesi, Matematik ve Fen Bilimleri Eğitimi Anabilim Dalı, ORCID ID: 0000-0003-3727-7516, E-posta: deryakaltakci@gmail.com
}

$\begin{array}{lll}\text { Gönderim: 27.03.2018 Kabul:15.06.2018 } & \text { Yayın:10.09.2018 }\end{array}$




\section{Comparison of Students' Answers to Context-Based and Traditional Questions on the Topic of Light Across Gender}

Abstract: In this casual comparative research study, it was aimed to compare the 6th, 7th and 8th grade elementary school students' answers to context-based and traditional questions on the topic of light across gender. Therefore, Light Achievement Tests (LATs) were developed for each grade level in accordance with 6th, 7th and 8th grade curriculum objectives. Each LAT consists of 20 multiple-choice questions; 10 are Context-Based Questions (CBQ) and 10 are traditional questions that are equivalent to the CBQ in terms of targeted objectives and cognitive level. The current study was carried out with 869 students (431 female and 438 male) in Izmit district of Kocaeli and the data were analyzed through MANCOVA test in SPSS 23.0 program. LATs' cronbach alpha reliability coefficients were found 0.794 for the 6 th grade, 0.785 for the 7 th grade and 0.824 for the 8 th grade level. According to MANCOVA results, there was no statistically significant difference between male and female students' LAT total scores, CBQ scores and traditional question scores in the 6th (Wilks' $\lambda=0.987, F(2,290)=1.966$, $p=0.142), 7$ th $($ Wilks' $\lambda=0.991, F(2,278)=1.257, p=0.286)$ and 8 th (Wilks' $\lambda=0.995$, $F(2,288)=0.732, p=0.482)$ grade levels. The findings were interpreted and recommendations were made to teachers, researchers, curriculum developers and related institutions.

Keywords: Science education, context-based questions, gender, light.

\section{Giriş}

Dünyada ve ülkemizde fen bilimleri dersi öğretim programlarının temel amacı fen okuryazarı bireyler yetiştirmektir (American Association for the Advancement of Science (AAAS), 1993; Milli Eğitim Bakanlığı (MEB), 2017; National Research Council (NRC), 1996). Bu amaç doğrultusunda öğretimde ve ölçme-değerlendirmede fen kavramlarının günlük 
yaşamla ilişkisine özellikle önem verilmektedir. Son yıllarda dünya çapında yapılan TIMSS (Uluslararası Matematik ve Fen Eğilimleri Araştırması) ve PISA (Uluslararası Öğrenci Değerlendirme Programı) gibi uluslararası sınavlarla ülkeler kendi eğitim-öğretim faaliyetlerini değerlendirme firsatı bulmakta ve buna yönelik çeşitli önlemler alma yoluna gitmektedir. Ülkemiz de bu sınavlarda istenilen başarıyı yakalayamayıp diğer ülkelerle kıyaslandığında son sıralarda yer almaktadır (MEB, 2016; OECD, 2016). Bunun en önemli nedeni, öğrencilerin öğrendikleri fen bilimleri ve matematik konularını günlük yaşamla bağdaştıramaması, bu nedenle de günlük yaşamla ilişkilendirilmiş bu sınavlardaki soruları çözmekte zorlanmasıdır. Bu nedenle hem öğretimde, hem de değerlendirme sürecinde fen bilimleri konularının günlük yaşamla ilişkilendirilmesi, dünya çapında yapılan bu sınavlardaki başarıyı beraberinde getireceği gibi genel olarak öğretimin kalitesini artırıp bilginin anlamlı ve kalıcı olmasına katkı sağlayacaktır (Bellocchi, King ve Ritchie, 2016; Nentwig, Demuth, Parchmann, Gräsel ve Ralle, 2007).

Öğrencilerin öğrendikleri bilgileri günlük yaşamda karşılaşabilecekleri sorunları çözmede kullanmalarının sağlanması açısından, ölçme ve değerlendirme faaliyetlerinde bağlam temelli soruların kullanılması oldukça önemlidir (Elmas ve Eryılmaz, 2015; İlhan ve Hoşgören, 2017). Bağlam temelli sorular (BTS), fen bilgisi konu veya kavramlarının bir bağlam ile örüntülenerek sorulduğu sorular olarak tanımlanabilir (Elmas ve Eryılmaz, 2015). BTS, gerçek nesne veya olaylar hakkında belirli hesaplamalar yapabileceğimiz nedenler içeren kısa hikayeler içerirler (Heller ve Hollabaugh, 1992). Bu kısa hikayelerde öğrenciye günlük yaşamından, deneyimlerinden veya ilgisini çeken bir bağlam ile zenginleştirilmiş soru yönlendirilir. Böylece, öğrenciler problemleri kendi yaşamları veya çevreden gözlemledikleri olaylar ile ilişkilendirerek çözüme ulaşmaya çalıştıklarında, üst düzey bilişsel seviyede düşünerek farklı çözüm yolları arayacak ve günlük yaşamlarında da problem çözme yaklaşımları gelişecektir (Rennie ve Parker, 1996; Tekbıyık ve Akdeniz, 2010). Bağlam temelli 
yaklaşıma dayalı değerlendirme sürecinin amacı öğrencinin ilgisini arttırmak, bağlam ve kavram ilişkisini kurdurmak, bilimin toplumdaki rolünü gösteren, ileride öğrenilecek kavramlar ve bağlamlarla ilgili merak uyandırmak ve öğrencilerin bilim ve teknoloji hakkındaki bilgilerini arttırmaktır (Fensham ve Rennie, 2013; akt. Bellocchi ve diğ., 2016). Gerçek hayat problemleriyle birçok ortak nokta barındıran BTS, öğrencilerin soyut ve zor olduğunu düşündükleri konu veya kavramları gerçek yaşamla ilgi çekici bir biçimde ilişkilendirip onların kolay şekilde problemi somutlaştırabilmesine ve çözüm yolu aramasına yardımcı olmaktadır (Heller ve Hollabaugh, 1992; Rennie ve Parker, 1996). Ahmed ve Pollitt (2007), BTS'lerin kullanılmasını üç nedene bağlamıştır; (i) Sadece hatırlamaya dayalı sorular sormak, kitaplardan bilgi ezberlemeye yöneltir. Bu da fen öğrenmenin önemini azaltan bir etkendir. (ii) Bağlam temelli sorular daha somut olduğundan, anlaşılması daha kolaydır. (iii) Bağlam temelli sorular, öğrencilerin hayatının içindendir. Alan yazında genel olarak BTS ile ilgili (Chu, Treagust ve Chandrasegaran, 2009; İlhan ve Hoşgören, 2017; McCullough, 2004; Palmer, 1997) veya BTS ile geleneksel soruların cevaplanma düzeylerinin karşılaştırıldığı (Akpınar, 2011; Georghiades, 2006; Heller ve Hollabaugh, 1992; Park ve Lee, 2004; Rennie ve Parker, 1996; Tekbıyık ve Akdeniz, 2010) çalışmalar mevcuttur ancak sayıca azdır.

Gerek öğretim sürecinde gerek değerlendirme sürecinde, seçilen bağlamların öğrencilerin ilgileri doğrultusunda seçilmesi önem taşımaktadır (Kaltakçı-Gürel, 2017). Bağlam seçiminde öğrencilerin yaş, cinsiyet, ilgi, bilişsel düzey ve deneyimlerinin dikkate alınması gerekir (Gilbert, 2006). Aksi halde öğrencilerin dikkatinin çekilmesi zor olabilir, derse olan ilgileri azalabilir veya değerlendirme sürecinde problemleri anlamakta güçlük çekebilirler (Hiscock, 1993). Bu sebeplerle hem kız hem de erkek öğrencilere hitap edecek bağlamlar seçilmelidir (Çekiç-Toroslu, 2011). Kız ve erkek öğrencilerin ilgi alanlarının farklı olduğu ve bu durumun fen bilgisi dersindeki konularda başarılarını etkilendiği bilinmektedir (Henetz ve Groutage, 1998; Jones, Howe ve Rua., 1999; Keeves ve Kotte, 1996; Sencar, 2001). Eğitimdeki 
cinsiyet eşitsizliğinin ve kız-erkek öğrenci grupları arasındaki uçurumun kapatılmasına yönelik uzun yıllardır yapılan akademik çalışmalara rağmen özellikle fen bilimleri, teknoloji, mühendislik ve matematik alanlarındaki uçurumlar hala birçok araştırmacının üzerinde çalıştığı temel sorunlar arasındadır (Baram-Tsabari ve Yarden, 2008; Dresel, Ziegler, Broome ve Heller, 1998; Tsai ve Huang, 2017). Bu uçurum özellikle fen bilimleri dersi fizik alanında daha dikkat çekicidir (McCullough, 2004; Zohar ve Sela, 2003). Kı̈ öğrenciler genel olarak fizik dersinde erkek öğrencilere göre daha düşük ilgi (Liu, Hu, Jiannong ve Adey, 2010; Reid ve Skryabina, 2003) ve başarıya (Baram-Tsabari ve Yarden, 2008; Zohar ve Sela, 2003) sahiptir. Kız öğrencilerin bu düşük performansı için alan yazında iki farklı açıklama getirilmiştir. Bunlardan ilki kız ve erkeklerin doğuştan gelen ve beyin yapılarındaki farklılıktan ötürü biyolojik faktörlerin öne çıtı̆̆g açıklamadır. Diğeri ise, özellikle son yıllarda üzerinde daha fazla durulan bireylerin içinde bulundukları kültürel ve sosyal ortamların etkisiyle oluşan farklılıklara dikkat çeken sosyo-kültürel açıklamadır (Hasse, 2002; Sencar ve Eryılmaz, 2004; Tsai ve Huang, 2017). Günümüzde hem okullarda hem de okul dış1 ortamlarda bu cinsiyet farklılı̆̆ını ve özellikle kız öğrencilerin fen bilimleri alanlarındaki dezavantajlı durumunu ortadan kaldırmak için çalışmalar devam etmektedir. Yapılan çalışmalarda genel olarak kız öğrencilerin fen bilgisi derslerinde insan vücudu ve insanların deneyimleri ile ilgili konularda daha başarılı iken, erkek öğrencilerin daha soyut işlenen fizik ve kimya konularında daha başarılı oldukları ortaya çıkmıştır (Keeves ve Kotte, 1992; Murphy, 1990; Qualter, 1993; akt. Reid ve Skryabina, 2003). Bunun nedeni olarak, k1z öğrenciler günlük yaşam ile ilişkilendirilmiş konu veya kavramları daha somut bulduklarından dolayı, yaşantıları olan insan ve insan ile ilgili biyolojik konulara ilgi duymakta ve bu konularda başarılı olmaktadır (Stewart, 1998). Alan yazında fizik dersinde erkek öğrencilerin özellikle elektrik (Yıldırım ve Eryılmaz, 1999), mekanik (Murphy ve Elwood, 1998; akt. Murphy ve Whitelegg, 2006) gibi konularda kız öğrencilere göre daha yüksek başarı, ilgi ve motivasyona sahip olduğunu ortaya 
koyan çalışmalar olsa da, 1şık konusu gibi diğer bazı konularda öğrencilerin özellikle günlük hayatla ilişkilendirilmiş problemleri çözebilme düzeylerinin karşılaştırıldı̆̆ı çalışmalar kisitlıdır (Benckert ve Pettersson, 2005; Chu ve diğ., 2009; McCullough, 2004; Park ve Lee, 2004; Rennie ve Parker, 1996). Bu çalışma alan yazındaki bu eksikliği gidermek adına yapılan önemli bir çalışmadır.

Araştırmanın temel amacı, ortaokul 6., 7. ve 8. sınıf öğrencilerinin 1şık konusundaki bilgilerini ölçmeye yönelik bağlam temelli sorular (BTS) ve geleneksel sorulardan oluşan testler geliştirip, kız ve erkek öğrencilerin bu testlerdeki BTS ve geleneksel soruları cevaplama düzeylerini karşılaştırmaktır. Bu çalışmada bu genel amaca yönelik olarak aşağıdaki araştırma sorusuna cevap aranmaktadir.

- Ortaokul 6., 7., ve 8. sınıf öğrencilerinin Işık Başarı Testi’nden aldıkları toplam puan, BTS'den aldıkları puan ve geleneksel sorulardan aldıkları puan arasında, fen bilgisi dersi karne notlarının etkisi kontrol edildiğinde cinsiyet açısından anlamlı bir fark var midir?

\section{Yöntem}

$\mathrm{Bu}$ araştırmanın yöntemi, nicel araştırma yöntemlerinden nedensel karşılaştırmalı araştırma yöntemidir. Nedensel karşılaştırmalı araştırma yöntemi, incelemeye konu olan durum veya olayın mevcut şartlar içerisinde gerçekleştikten sonra ortaya çıkan farklılıkların sebeplerinin ya da gruplar arasında var olan farklılıkların ne tür sonuçlara yol açtığının incelendiği çalışmalardır (Sözbilir, 2014).

\section{Evren ve Örneklem}

Bu araştırmanın evrenini Kocaeli ilinin İzmit ilçesinde 2016-2017 eğitim öğretim yılında öğrenim gören 13135 (\% 51.26’ü erkek, \% 48.74'si kız) 6., 7. ve 8. sınıf öğrencisi oluşturmaktadır. Çalışma için İzmit ilçesindeki 41 ortaokuldan 12 ortaokul Türkiye genelinde 
yapılan 2014 yılı Temel Eğitimden Ortaöğretime Geçiş (TEOG) sınavının sonuçlarına göre yüksek başarı, orta başarı ve düşük başarı gösteren okullar olmak üzere üç gruba ayrılmış ve başarı açısından benzer bir şekilde seçilmiştir. Çalışmanın örneklemi bu belirlenen 12 ortaokulda 6., 7. ve 8. sınıflarda öğrenim gören öğrenciler arasından cinsiyet ve sınıf düzeyine göre tabakalı örneklem yoluyla belirlenmiştir. Çalışmada 431 (\% 49.6) kız ve 438 (\% 50.4) erkek öğrenci olmak üzere toplam 869 öğrenci bulunmaktadır. Örneklemi oluşturan öğrenci sayılarının cinsiyet ve sınıf düzeyine göre dağılımı Tablo 1'de gösterilmiştir.

Tablo 1. Örneklemi oluşturan ögrencilerin cinsiyet ve sınıf düzeyine göre dă̆llımı

\begin{tabular}{|c|c|c|c|c|c|}
\hline \multirow[t]{2}{*}{ Sınıf Düzeyi } & Erkek öğrenci sayısı & \multicolumn{2}{|c|}{ Kız öğrenci sayısı } & \multicolumn{2}{|c|}{ Toplam } \\
\hline & $\%$ & $\mathrm{~N}$ & $\%$ & $\mathrm{~N}$ & $\%$ \\
\hline 6. sinif & $137(\% 46.6)$ & 157 & $(\%$ 53.4) & 294 & $\% 33.8)$ \\
\hline 7. sinif & $142(\%$ 50.4) & 140 & $(\% 49.6)$ & 282 & $\% 32.5)$ \\
\hline 8. sinif & $159(\% 54.5)$ & 134 & $(\%$ 45.5) & 293 & $\%$ 33.7) \\
\hline Toplam & $438(\% 50.4)$ & 431 & $(\%$ 49.6) & 869 & $\%$ 100) \\
\hline
\end{tabular}

\section{Veri Toplama Araçları}

Bu çalışmada veri toplama aracı olarak araştırmacılar tarafından geliştirilen ve ortaokul 6., 7. ve 8. sınıf fen bilgisi dersi 1şık konularını içeren Işık Başarı Testi (IBT) kullanılmıştır. IBT her bir sınıf için, sınıfın bilişsel düzeyine ve öğretim programı kazanımlarına uygun olarak, on tane BTS ve bu on soruya bilişsel düzey ve kazanımlara uygunluk açısından denk olan on tane geleneksel soru olmak üzere 20 çoktan seçmeli sorudan oluşmaktadır. Şekil 1.'de 6. sınıf IBT'de yer alan bir BTS ve aynı testten ona denk bir geleneksel soru örnek olarak verilmiştir. 


\section{BTYDS}

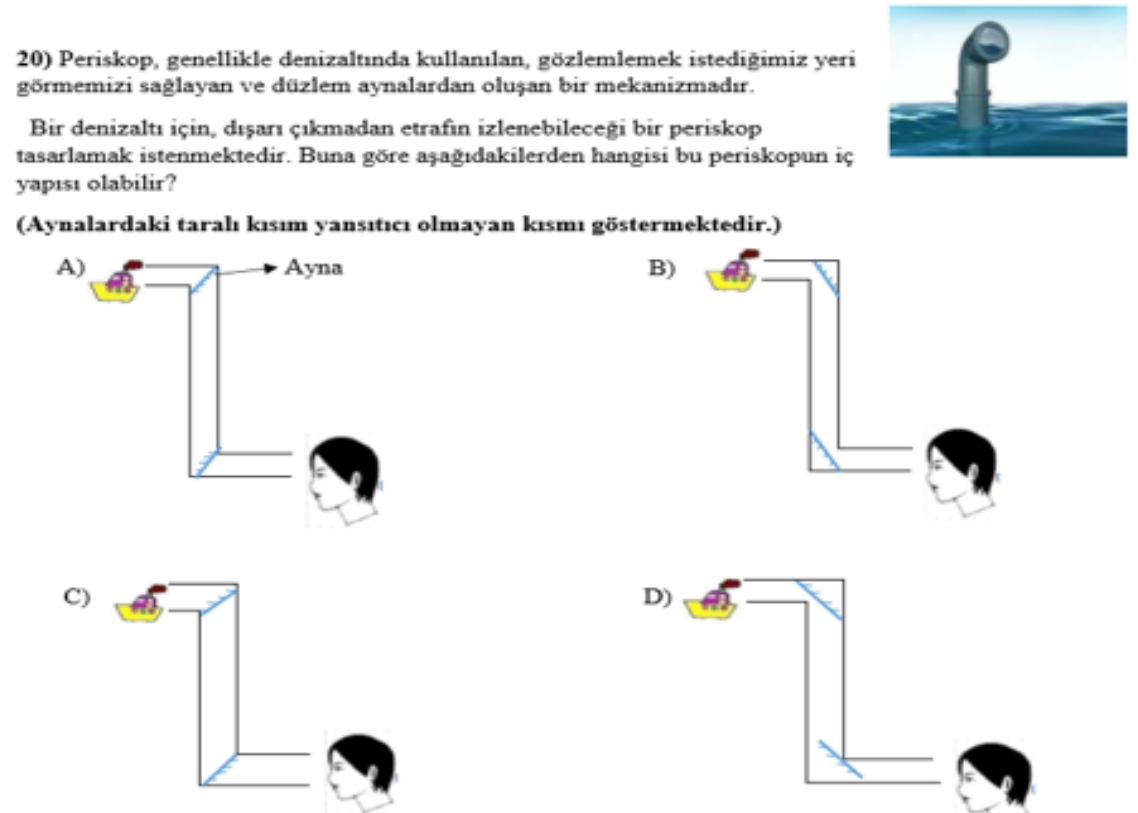

Geleneksel soru

19)

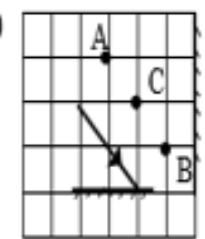
A) A
B) $A$ ve $B$
C) $B$
D) $\mathrm{BreC}$

Şekilde görïldiğũi gibi bir düzlem aynaya 1şın gönderiliyor ve yansıyan șin diğger aynadan da yansiyarak ortamı terk ediyor. Buna gōore yansıyan șin ortamı terk edene kadar $A, B$ ve C noktalarınin hangisi veya hangilerinden geçmektedir?

\section{(Aynalardaki tarah kısım yansıticı olmayan kısmı} göstermektedir.)

6.4.1.1. Işı̆̆ı̆ düzgün ve pürüzlü yüzeylerdeki yansımalarını gözlemler ve ışınlar çizerek gösterir.

Şekil 1. Şekil 1. 6. sınıf IBT'den BTS ve geleneksel soru örneği ve ilgili öğretim programı kazanımı 


\section{Geçerlik ve Güvenirlik}

Hazırlanan IBT'lerin kapsam geçerliğinin sağlanması için, soruların kazanımlara uygun olması ve tüm kazanımları kapsamasını sağlamak amacıyla belirtke tabloları oluşturulmuştur. Alan eğitimci üç öğretim üyesi ve MEB'de görev yapan bir fen bilgisi öğretmeni olmak üzere toplam dört uzmandan görüş alınıp uzman görüşleri neticesinde testlerde gerekli düzeltmeler yapılmıştır. Testlerin geçerlik ve güvenirliği sağlanması için ilçedeki iki ortaokulda 6., 7. ve 8. sınıfta öğrenim gören 212 öğrenciye (\% 56.6 kız, \% 43.4 erkek) pilot çalışma olarak uygulanmıştır. Her sorunun madde ayırtedicilik ve zorluk katsayıları madde analizi yapılarak incelenmiş ve sorunlu sorular düzeltilerek veya çıkarılarak testler iyileştirilmiştir. Pilot çalışmada Cronbach alfa güvenirlik katsayıları her sınıf seviyesindeki iyileştirilen IBT testi için ayrı ayrı hesaplanmıştır. Buna göre; 6. sınıf IBT için 0.722, 7. sınıf IBT için 0.873, 8. sınıf IBT için $0.775^{\prime}$ tir.

Pilot çalışma sonrası gerçekleştirilen uygulamada ortalama madde güçlük katsayısı $(P j)$ her sınıf seviyesindeki IBT testi için ayrı ayrı hesaplanmıştır. Madde güçlük katsayısı, bir testteki maddeye doğru cevap veren öğrenci sayısının, örneklemdeki tüm öğrencilerin sayısına oranı olarak tanımlanmaktadır (Can, 2016). Testteki maddelerin güçlük katsayısının 0.20 ile 0.80 arasında olması beklenmek ile birlikte, testin genel ortalama madde güçlük katsayısının 0.50 olmas1 istenmektedir (Doran, 1980; Kubiszyn ve Borich, 2003; Tosun ve Taşkesenligil, 2011; akt, İlhan ve Hoşgören, 2017). Uygulama sonrasında yapılan madde analizlerine göre 6. sinıf $(P j=0.638), 7$. sınıf $(P j=0.746)$, ve 8 . sinıf $(P j=0.631)$ seviyesi için hesaplanan IBT ortalama madde güçlük katsayılarının kolay olduğu görülmektedir. Madde ayırtedicilik katsayısı $\left(r_{j} x\right)$, bir test sonucu üst grupta bulunan yüksek başarı gösteren öğrencilerin doğru cevapları ile alt grupta bulunan düşük başarı gösteren öğrencilerin doğru cevaplarının karşılaştırılması olarak tanımlanır (Can, 2016) ve geçerlik için kullanılır. Madde ayırtedicilik katsayıları aralıkları 0.40 'tan büyük ise madde veya test çok iyi, 0.40-0.30 arasında ise madde 
veya test iyi, 0.30-0.20 arasında ise kullanılması zorunlu ise madde veya test kullanılabilir veya düzeltilmeli ve 0.20 'den küçük ise madde çıkartılmalı veya düzeltilmelidir (Turgut, 1992; akt. Gönen, Kocakaya ve Kocakaya, 2011). Uygulama sonrasında yapılan madde analizlerine göre 6. $\sin 1 f\left(r_{j} x=0.489\right), 7 . \sin ı f\left(r_{j} x=0.440\right)$ ve $8 . \sin 1 f\left(r_{j} x=0.518\right)$ için hesaplanan IBT ortalama madde ayırtedicilik katsayılarına bakıldığında, her sınıf seviyesindeki test için ayırtediciliğin yüksek olduğu söylenebilmektedir. Bir testin, iç tutarlığının göstergesi olarak tanımlanan Cronbach alfa güvenirlik katsayıları ise $6 . \sin ı f(\alpha=0.794), 7 . \sin 1 f(\alpha=0.785)$ ve 8 . sinıf seviyesi için $(\alpha=0.824)$ testlerin güvenilirliğinin kabul edilebilir olduğunu göstermektedir.

\section{Uygulama Süreci}

Test geliştirme sürecinde gerekli alan yazın taramalarından sonra, ortaokul öğrencilerinin 1şık konusunda BTS çözebilmeleri ile ilgili çalışmalar açısından eksiklik görülmüş ve bu konu ile ilgili çalışmalar incelenmiştir. Ardından 6., 7. ve 8. sınıf fen bilgisi dersi ışık konusu kazanımlarıyla uyumlu BTS ve bu sorulara denk olan geleneksel sorular geliştirildikten sonra uzman görüşü alınıp tekrar düzenlenmiş ve pilot çalışma uygulanmıştır. Pilot çalışma sonucu madde analizleri yapılmış ve Cronbach alfa güvenirlik katsayısı bulunmuştur. Sorunlu sorular çıkarılıp IBT'ler uygulamaya hazır hale gelmiştir.

Uygulama toplam sekiz günde tamamlanmıştır. Uygulamada öğrencilere çoktan seçmeli soruların bulunduğu testin yanı sıra öğrencilerin cinsiyetlerini, fen bilgisi dersi karne notlarını, sınıf düzeylerini ve cevaplarını işaretleyebilecekleri optik form verilmiştir. Uygulama her sınıf için bir ders saati (40 dakika) sürmüştür. Araştırmacı uygulama esnasında, uygulama yapılan her sınıfta öğretmen ile beraber bulunmuş, optik formların nasıl doldurulacağ 1 hakkında bilgiler vermiş ve öğrencilerin bilgilerini eksiksiz doldurup doldurmadığını kontrol etmiştir. Uygulama tamamlandıktan sonra öğrenci bilgileri ve cevaplar analizleri yapılmak üzere bilgisayar ortamına aktarılmıştır.

\section{Veri Analizi}


Öğrencilerin testlerdeki verdikleri doğru cevaplara 1 , yanlış cevaplara 0 puan verilerek diğer demografik bilgilerle birlikte veriler MS-Excel programına girilmiştir. Madde analizleri TAP (Test Analysis Program); Cronbach alfa güvenirlik katsayıları, MANCOVA (Multivariate Analysis of Covariance) analizi ise SPSS 23.0 programı ile yapılmıştır. Bu programlar yardımıyla ilk olarak her sınıf için ayrı ayrı kayıp veri analizi yapılmış ve testteki soruların \%50'sinden fazlasını boş bırakan bir öğrencinin verileri analizden çıkarılmıştır. Çalışmanın örneklem sayısı 868 olarak analizlere devam edilmiştir.

Madde analizi için madde ayırtedicilik ve güçlük katsayıları hesaplanmış ve yorumlanmıştır. Çalışmanın araştırma sorusuna cevap bulabilmek için öncelikle gerekli sayıltıların sağlanıp sağlanamadığı kontrol edilmiş, ardından MANCOVA testi yapılmıştır. Tablo 2.'de MANCOVA testinde kullanılan değişkenler ve kovaryans belirtilmiştir.

Tablo 2. MANCOVA'da kullanılan değişsenler ve kovaryans

\begin{tabular}{cc}
\hline Veri türü & Veri adı \\
\hline Kovaryans & Fen bilgisi karne notu \\
Grup 1 (bağımsız değişken) & Cinsiyet (kız, erkek) \\
Grup 2 (bağımlı değişken) & Toplam puan, BTS puan ve geleneksel soru puanı \\
Grup 1* kovaryans & Cinsiyet* fen bilgisi karne notu \\
\hline
\end{tabular}

\section{Bulgular}

Her sınıf seviyesinde IBT'den alınabilecek en yüksek puan 100, BTS ve geleneksel sorulardan alınabilecek en yüksek puan ise 50'dir. Buna göre, her sınıf seviyesi için IBT puanlarının merkezi dağılımı Tablo 3'te incelenmiştir. Bağımlı değişkenlerden IBT toplam puan ortalaması 6. sınıf seviyesi için 63.78 ( $S . S=20.22)$; 7. sınıf için 74.59 (S.S=18.96); 8. sınıf için 63.12 (S.S=21.67)'dir. Her sınıf seviyesi için IBT puan türlerinde, çarpıklık ve basıklık 
YYÜ Ĕ̌itim Fakültesi Dergisi (YYU Journal of Education Faculty), 2018; 15(1):672-697, http://efdergi.yyu.edu.tr http://dx.doi.org/10.23891/efdyyu.2018.83

değerlerinin -1 ile +1 arasında olması (Morgan, Leech, Gloeckner ve Barret, 2004; akt, Can, 2016), IBT puanlarının normal dağılım gösterdiğini kanıtlamaktadır.

Tablo 3. 6., 7. ve 8. sinıflar için puan türlerine göre tanımlayıcı istatistik değerleri

\begin{tabular}{|c|c|c|c|c|c|c|c|c|c|c|}
\hline Sinıf & $\mathrm{N}$ & Puan türü & Ortalama & Mod & $\begin{array}{c}\text { En } \\
\text { yüksek } \\
\text { puan }\end{array}$ & $\begin{array}{c}\text { En } \\
\text { düşük } \\
\text { puan }\end{array}$ & Medyan & $\begin{array}{c}\text { Standart } \\
\text { sapma }\end{array}$ & Çarpıklık & Basıklık \\
\hline \multirow{4}{*}{6} & \multirow{4}{*}{294} & $\begin{array}{c}\text { Toplam } \\
\text { puan }\end{array}$ & 63.78 & 85.00 & 100.00 & 10.00 & 65.00 & 20.22 & -0.445 & -0.536 \\
\hline & & BTS puan & 33.28 & 35.00 & 50.00 & 5.00 & 35.00 & 10.43 & -0.675 & -0.099 \\
\hline & & $\begin{array}{l}\text { Geleneksel } \\
\text { soru puan }\end{array}$ & 30.49 & 35.00 & 50.00 & 5.00 & 35.00 & 12.21 & -0.308 & -0.900 \\
\hline & & $\begin{array}{c}\text { Fen bilgisi } \\
\text { karne notları }\end{array}$ & 82.69 & 90.66 & 100.00 & 34.50 & 87.75 & 15.38 & -1.170 & 0.686 \\
\hline \multirow{4}{*}{7} & \multirow{4}{*}{282} & $\begin{array}{c}\text { Toplam } \\
\text { puan }\end{array}$ & 74.59 & 75.00 & 100.00 & 15.00 & 80.00 & 18.96 & -0.900 & 0.343 \\
\hline & & BTS puan & 36.38 & 45.00 & 50.00 & 5.00 & 40.00 & 10.97 & -0.819 & 0.026 \\
\hline & & $\begin{array}{l}\text { Geleneksel } \\
\text { soru puan }\end{array}$ & 38.20 & 45.00 & 50.00 & 5.00 & 40.00 & 9.82 & -0.841 & 0.277 \\
\hline & & $\begin{array}{c}\text { Fen bilgisi } \\
\text { karne notları }\end{array}$ & 77.08 & 78.00 & 100.00 & 34.83 & 78.55 & 15.42 & -0.496 & -0.622 \\
\hline \multirow{4}{*}{8} & \multirow{4}{*}{292} & $\begin{array}{l}\text { Toplam } \\
\text { puan }\end{array}$ & 63.12 & 80.00 & 95.00 & 10.00 & 65.00 & 21.67 & -0.426 & -0.894 \\
\hline & & BTS puan & 32.19 & 45.00 & 50.00 & 5.00 & 35.00 & 11.92 & -0.287 & -0.877 \\
\hline & & $\begin{array}{l}\text { Geleneksel } \\
\text { soru puan }\end{array}$ & 30.92 & 40.00 & 50.00 & 0.00 & 35.00 & 11.43 & -0.591 & -0.663 \\
\hline & & $\begin{array}{c}\text { Fen bilgisi } \\
\text { karne notları }\end{array}$ & 84.19 & 100.00 & 100.00 & 35.00 & 89.83 & 15.68 & -1.038 & 0.086 \\
\hline
\end{tabular}


Araştırma sorusu olan “'Ortaokul öğrencilerinin Işık Başarı Testi’nden aldıkları toplam puan, BTS'den aldıkları puan ve geleneksel sorulardan aldıkları puan arasında, fen bilgisi dersi karne notlarının etkisi kontrol edildiğinde cinsiyete göre anlamlı bir fark var mıdır?“ için MANCOVA analizi yapılmıştır. MANCOVA analizi yapabilmek için bazı sayıltıların sağlanması gerekmektedir. Bu sayıltılar; (1) normallik, (2) regresyon homojenliği, (3) kovaryans ve bağımlı değişkenler arasındaki korelasyon ilişkisi, (4) kovaryans eşitliği (Box testi), (5) varyans eşitliği (Levene testi), (6) çok boyutluluk ve (7) bağımsızlık varsayımıdır. Buna göre: (1) Tanımlayıcı istatistik değerlerinin yorumlanmasında daha önce belirtildiği üzere, normalliğin sağlandığı varsayılmıştır. (2) Regresyon homojenliği varsayımı, bağımlı değişken ile kovaryanslar (Blok 1) arasındaki ilişkinin, bağımsız değişkenler (Blok 2) üzerinde aynı olması anlamına gelir. Regresyon homojenliğini test etmek için çok değişkenli regresyon analizi (MRC) yöntemi kullanarak $R^{2}$ değişimi test edilmiştir. Bu analiz için kovaryans ile bağımsız değişken çarpılarak etkileşim değişkeni (Blok 3) oluşturulmuştur. MRC analizi ile $R^{2}$ değişiminin anlamlılığı test edilmiş, her sınıf seviyesi için bağımlı değişken IBT toplam puana göre: 6. sınıf seviyesi için $(F(1,290)=0.103, p=0.748)$, 7. sınıf seviyesi için $(F(1,278)=0.340$, $p=0.561)$ ve 8 . sınıf seviyesi için $(F(1,288)=0.121, p=0.728)$ Blok 3'ün $R^{2}$ değişiminde anlamlı bir etkileşim etkisi görülmemiş ve MRC sonucu regresyon homojenliklerinin sağlandiğ görülmüştür. (3) Kovaryans olan fen bilgisi karne notu, bağımlı değişkenler olan IBT toplam puan, BTS puan ve geleneksel puan türlerinin birbirleri ile olan korelasyon ilişkisinin anlamlı düzeyde olması $(p<0.01)$ ve Pearson korelasyon katsayısının pozitif olması gerekir. Her sınıf seviyesi için kovaryans ve bağımlı değişkenlerin arasında anlamlı düzeyde ilişki olduğu bulunmuş, Pearson korelasyon katsayılarının pozitif olduğu görülmüştür. Burada Pearson korelasyon katsayılarının 0.90'dan küçük olması beklenmektedir. Büyük olması halinde, kovaryans olan fen bilgisi karne notları ile bağımlı değişkenler olan IBT puan türleri arasında çok bağlantılılık (aşırı derecede yüksek ilişki) söz konusu olacaktır ve çoklu bağlantılılık 
istenmeyen bir durumdur (Can, 2016). Çalışmada bağımlı değişkenler ile kovaryans arasındaki Pearson korelasyon katsayıları açısından çoklu bağlantılılık söz konusu değildir $(r<0.90)$. (4) Box matrislerin eşitliği testi, varyans-kovaryans matrislerinin eşitliğini analiz eden bir testtir ve matrisler arasında anlamlı fark olmaması esastır. 6. sınıflar için yapılan Box kovaryans matrislerinin eşitliği testinde $(p=0.692>0.05), 7$. sınıflar için $(p=0.103>0.05), 8$. sınıflar için $(p=0.189>0.05)$ bulunması matrisler arasında anlamlı bir fark olmadığını göstermektedir. (5) Levene testi, hata varyansları arasında anlamlı bir fark olup olmadığını gösteren bir testtir ve hata varyansları arasında anlamlı bir fark olmaması gerekmektedir. Levene testi sonuçlarında bakıldığında, 7. sınıflarda BTS puan türünde $(p=0.004<0.05)$ ve toplam puan türünde $(p=0.003$ $<0.05)$, hata varyansları arasında anlamlı bir fark görülmektedir. Ayrıca 8. sınıflarda BTS puan türünde $(p=0.032<0.05)$ anlamlı fark çıkmıştır. $\mathrm{Bu}$ durum MANCOVA sayıltısını sağlamamaktadır. Box (1954)'e göre karşılaştırılan gruplardaki öğrenci sayılarının birbirine eşit veya yakın olması, bu testi çok etkilememektedir (Gökalp, 2011). 7. ve 8. sınıf seviyesinde bazı puan türlerinde, hata varyansları arasında anlamlı bir fark çıkması MANCOVA yapılmasını engelleyen çok önemli bir sorun olarak görülmemektedir. (6) Çokboyutluluk varsayımı, kovaryanslar arasındaki korelasyon katsayının 0.80 'in altında olmasını öngörür (Stevens, 2009). Bu çalışmada tek kovaryans olarak fen bilgisi karne notu dikkate alındığından, çok boyutluluk varsayımının sağlandığı varsayılabilir. (7) Bağımsızlık varsayımı araştırmacının testlerin uygulanması sırasındaki gözlemleri ile karşılanmıştır. Testi yapan öğrencilerin testi kendi başlarına yaptıkları gözlemlenmiş, araştırmacı ortam ile etkileşime girmemiştir.

Her sınıf seviyesi için ayrı ayrı yapılan MANCOVA testi sonuçlarına göre; 6. sınıf IBT toplam puan, BTS puan ve geleneksel soru puanlarında kız ve erkek öğrenciler arasında anlamlı bir fark bulunmamıştır (Wilks’ $\lambda=0.987, F(2,290)=1.966, p=0.142$ ). 7. sınıf IBT toplam puan, BTS puan ve geleneksel soru puanlarında kız ve erkek öğrenciler arasında anlamlı bir fark 
bulunmamıştır (Wilks' $\lambda=0.991, F(2,278)=1.257, p=0.286$ ). 8. sınıf IBT toplam puan, BTS puan ve geleneksel soru puanlarında da kız ve erkek öğrenciler arasında anlamlı bir fark bulunmamıştır (Wilks' $\lambda=0.995, F(2,288)=0.732, p=0.482$ ). Her sınıf seviyesi için ayrı ayrı yapılan MANCOVA testi sonuçlarına göre cinsiyetin IBT puan türlerine istatistiksel olarak anlamlı etkisi bulunmadığından, cinsiyetin ayrı ayrı her bir puan türüne etkisini analiz eden ANCOVA testi yapılmamıştır. Sonuç olarak 6., 7. ve 8. sınıfta öğrenim gören kız ve erkek öğrencilerin 1şık konusunda hazırlanan IBT'lerdeki tüm soruları, testteki BTS'leri ve testteki geleneksel soruları çözebilme düzeyleri arasında anlamlı bir fark bulunamamıştır.

\section{Tartışma ve Yorum}

Bağlam temelli sorular (BTS), öğrencilerin günlük hayatla bağdaştırabileceği, ilgi duydukları veya deneyimleri ile ilgili bağlamların sorular içine yerleştirilerek, öğrencilerin özellikle fen bilimleri dersi konularına ilgi duyması ve bu dersteki başarılarını sağlamak amacıyla geliştirilen sorulardır (Ahmed ve Pollitt, 2007). Bu çalışmada her sınıf seviyesinde kız ve erkek öğrencilerin IBT toplam puanları arasında anlamlı bir fark bulunamaması, kız ve erkek öğrenciler arasında ışık konusu ile ilgili soruları çözebilme düzeyleri arasında anlamlı fark olmadığını göstermektedir. Alan yazında bahsedildiği gibi, kız ve erkek öğrencilerin farklı ilgilerinin olduğu ve bunun fen bilimleri dersi konularındaki başarılarını etkilediği bilinmektedir. Birçok konuda başarı olarak farklı oldukları düşünülen kız ve erkek öğrencilerin, 1şık konusunda aralarında başarı açısından fark çıkmaması dikkate değer bir sonuçtur. Yapılan çalışmalarda özellikle fen bilimleri dersi fizik alanında erkek öğrencilerin kız öğrencilere göre daha başarılı olduğu görülmüşs (Dresel ve diğ., 1998; Yıldırım ve Eryılmaz, 1999), bunun sonucunda özellikle fizikte kız öğrenciler ile erkek öğrenciler arasındaki bu uçurumun kapatılmasına yönelik çeşitli önlemler alınıp bu konuda daha fazla akademik araştırmalar yapılması önerilmiştir. Ancak bu konudaki çalışmaların genel olarak fizik dersindeki başarı (Dresel ve diğ., 1998; Yerdelen-Damar ve Peşman, 2013) veya elektrik, mekanik gibi yalnızca 
belli fizik konularındaki başarıyı (Kılıç, 2009; McCullough, 2004; Sencar, 2001; Yıldırım ve Eryılmaz, 1999) karşılaştıran çalışmalar olduğu ve bazı diğer fizik konularının daha az sayıda araştırmaya konu olduğu dikkat çekmektedir. Diğer derslerde olduğu gibi fizik dersindeki başarının da konu spesifik olabileceği düşünüldüğünde kız ve erkek öğrencilerin eşit başarıya sahip olduğu konuların tespitinin alan yazınına katkı sağlayacağı düşünülmektedir. Bu açıdan, bu çalışmada kız ve erkek öğrenciler arasında, 1şık konusu sorularını çözebilme düzeylerinde anlamlı fark çıkmaması, önemli bir sonuç olarak değerlendirilmektedir. Araştırmanın sonucunda 6., 7. ve 8. sınıfta öğrenim gören kız ve erkek öğrencilerin BTS ve geleneksel sorular puanları arasında anlamlı bir fark çıkmaması, kız ve erkek öğrencilerin tüm testteki sorularda olduğu gibi ayrı ayrı BTS ve geleneksel sorularda da eşit başarı sergilediği sonucunu göstermiştir. $\mathrm{Bu}$ sonuca göre, kız ve erkek öğrencilerin 1şık konusunu günlük yaşam ile ilişkilendirebilme düzeylerinin eşit olduğu söylenebilir. Benzer şekilde Rennie ve Parker (1996) kuvvet ve hareket konusunda BTS ve geleneksel soruları karşılaştırdıkları çalışmada, kız ve erkek öğrenciler arasında iki puan türüne göre de fark bulamamışlardır. Son yıllarda kız ve erkek öğrencilerin fen bilimleri konularında eşit deneyimler kazandırılması ve bilime karşı tutumlarının, şuanda ve gelecekte de bilim ile ilgili çalışmalara yönelmelerinin eşit olabilmesi önem kazanmıştır (McCullough, 2004). Erkek öğrencilerin fen bilimleri dersi fizik alanında kız öğrencilere göre daha başarılı olduğu ve bunun sonucunda kız öğrencilerin fizik alanına önyargılı yaklaştığı bilinmektedir (Liu ve diğ., 2010). Bu nedenle öğrenciler, toplumun etkisiyle de fizik alanıyla ilgili mesleklerin genellikle erkek öğrencilerin seçtiği meslek grubu olarak düşünmektedir (Murphy ve Whitelegg, 2006). Bu açıdan fen bilimleri dersi fizik alanında 1şık konusu gibi kız ve erkek öğrencilerin aynı derecede başarılı olduğu fizik konularının tespit edilmesi, özellikle kız öğrencilerin bu derse olan ilgi, motivasyon ve başarılarını artırıp önyargılarının azalmasına sebep olabileceği ve böylece ileride fizik ile ilgili meslek gruplarında daha fazla kız öğrencinin görülebilmesini sağlayacağı düşünülmektedir. 
Kız öğrencilerin her alanda erkek öğrenciler ile eşit olması, cinsiyet farklılıklarının en aza indirgenmesi ve ortadan kaldırılmasında öğretmenlerin, müfredat geliştiricilerin, araştırmacıların ve MEB gibi kurumların sorumlulukları oldukça fazladır. Çalışmada elde edilen sonuçlar doğrultusunda, ögretmenlere, bağlam temelli yaklaşıma dayalı öğretim ve değerlendirmenin 1şık konusunda olduğu gibi derslerdeki diğer fen konularında da kullanılması; $M E B$ 'e, öğretmenlere yönelik bağlam temelli yaklaşıma dayalı öğretim ve soruların kullanılmasıyla ilgili hizmet içi eğitim veya çalıştayların yapılması, liselere giriş sınavlarında uluslar arası testlerdeki başarıyı yakalayabilmek için daha fazla günlük hayatla bağdaştırılmış BTS'lerin teşvik edilmesi; araştırmacılara, deney ve kontrol grupları oluşturularak 1şık konusunda bağlam temelli yaklaşıma dayalı öğretim ve geleneksel öğretim uygulanması şeklinde yapılacak olan deneysel çalışmalarda değerlendirme sürecinde BTS ile geleneksel sorulardan oluşan IBT'ler uygulanması ve böylece öğretimin bu iki soru türüne etkisinin araştırılması, fen bilimleri dersi 1şık konusu dışındaki diğer konularda da BTS ve eşleniği olan geleneksel sorular geliştirilerek, kız ve erkek öğrencilerin bu soru türlerindeki başarı düzeylerinin karşılaştırılması, BTS'lerden oluşan testlerin fen bilgisi dersindeki diğer konular ile matematik, kimya, biyoloji gibi farklı disiplinlerde de uygulanarak etkilerinin belirlenmesi, daha geniş örneklemler ve bölgelerde benzer araştırmaların yapılarak araştırma sonuçlarının bu çalışmanın sonuçları ile karşılaştırılması; müfredat gelişstiricilere ise, öğrencilerin ilgisini çeken ve günlük yaşantılarıyla bağdaştırabileceği hikayeler içeren BTS'lerin hem öğretim programlarında hem de ders kitaplarında daha fazla yer etmesi önerilmektedir.

Bu araştırma 2016-2017 eğitim-öğretim yılında yalnızca Kocaeli ili İzmit ilçesinde seçilen 12 okulda öğrenim gören 6., 7. ve 8. sınıflardan 1şık konusunda elde edilen verilerle sinırlidir.

\section{Makalenin Bilimdeki Konumu (Yeri)}


Matematik ve Fen Bilimleri Eğitimi Bölümü, Fen-Fizik Eğitimi Anabilim Dalı

\section{Makalenin Bilimdeki Özgünlüğü}

Birçok konuda başarı olarak farklı oldukları düşünülen kız ve erkek öğrencilerin, bu çalışmada geliştirilen ve bağlam temelli ve geleneksel sorulardan oluşan 1şık konusundaki testlerde ortaokul 6., 7., ve 8. sınıf seviyelerinde aralarında başarı açısından fark çıkmaması dikkate değer bir sonuçtur. Yapılan çalışmalarda özellikle fen bilimleri dersi fizik alanında erkek öğrencilerin kız öğrencilere göre daha başarılı olduğu görülmüş, bunun sonucunda özellikle fizikte kız öğrenciler ile erkek öğrenciler arasındaki bu uçurumun kapatılmasına yönelik çeşitli önlemler alınıp bu konuda daha fazla akademik araştırmalar yapılması önerilmiştir. Ancak bu konudaki çalışmaların genel olarak fizik dersindeki başarı veya elektrik, mekanik gibi yalnızca belli fizik konularındaki başarıyı karşılaştıran çalışmalar olduğu ve bazı diğer fizik konularının daha az sayıda araştırmaya konu olduğu dikkat çekmektedir. Diğer derslerde olduğu gibi fizik dersindeki başarının da konu spesifik olabileceği düşünüldüğünde kız ve erkek öğrencilerin eşit başarıya sahip olduğu konuların tespitinin alan yazınına katkı sağlayacağı düşünülmektedir. Bu açıdan, bu çalışmada kız ve erkek öğrenciler arasında, 1şık konusu sorularını çözebilme düzeylerinde anlamlı fark çıkmaması, önemli bir sonuç olarak değerlendirilmektedir.

\section{Kaynaklar}


Ahmed, A., \& Pollitt, A. (2007). Improving the quality of contextualized questions: An experimental investigation of focus. Assessment in Education, 14(2), 201-232.

Akpınar, M. (2011). Bă̆lam temelli yaklaşımla yapılan fizik ĕgitiminde kavramsal değişim metinlerinin öğrenci erişisine etkisi. Yayımlanmamış doktora tezi, Eğitim Bilimleri Enstitüsü, Gazi Üniversitesi, Ankara.

American Association for the Advancement of Science (AAAS) (1993). Benchmarks for scientific literacy: A project report 2061 report. NY: Oxford University press.

Baram-Tsabari, A., \& Yarden, A. (2008). Girls’ biology, boys' physics: evidence from freechoice science learning settings. Research in Science \& Technological Education, 26(1), 75-92.

Bellocchi, A., King, D. T., \& Ritchie, S. M. (2016). Context-based assessment: creating opportunities for resonance between classroom fields and societal fields. International Journal of Science Education, 38(8), 1304-1342.

Benckert, S., \& Pettersson, S. (2005). Conversation and context in physics education. Myndigheten För Nätverk Och Samarbete Inom Högre Utbildning, 1(13) http://hdl.handle.net/2077/18144 adresinden alınmıştır.

Can, A. (2016). SPSS ile Bilimsel araştırma sürecinde nicel veri analiz (4. baskı). Ankara: Pegem Akademi.

Chu, H. E., Treagust, D. F., \& Chandrasegaran, A. L. (2009). A stratified study of students' understanding of basic optics concepts in different contexts using two-tier multiplechoice items. Research in Science \& Technological Education, 27(3), 253-265.

Çekiç-Toroslu, S. (2011). Yaşam temelli öğrenme yaklaşımı ile desteklenen 7 E ögrrenme modelinin öğrencilerin enerji konusundaki başarı, kavram yanılgısı ve bilimsel süreç becerilerine etkisi. Yayımlanmamış doktora tezi, Eğitim Bilimleri Enstitüsü, Gazi Üniversitesi, Ankara. 
Doran R. L. (1980). Basic measurement and evaluation of science instruction. Washington, DC: NSTA Press.

Dresel, M., Ziegler, A., Broome, P., \& Heller, K. A. (1998). Gender differences in science education: The double-edged role of prior knowledge in physics. Roeper Review, 21(2), 101-106.

Elmas, R., \& Eryılmaz, A. (2015). How to write good quality contextual science questions: criteria and myths. Journal of Theoretical Educational Science/Kuramsal Eğitimbilim Dergisi, 8(4), 564-580.

Georghiades, P. (2006). The role of metacognitive activities in the contextual use of primary pupils' conceptions of science. Research in Science Education, 36(1-2), 29-49.

Gilbert, J. K. (2006). On the nature of 'context' in chemical education. International Journal of Science Education, 28(9), 957-976.

Gökalp, M.S. (2011). The effect of webquest based instructıon on ninth grade students' achievement in and attitude towards force and motion. Yayımlanmamış doktora tezi, Ortadoğu Teknik Üniversitesi, Ankara.

Gönen, S., Kocakaya, S., \& Kocakaya, F. (2011). Dinamik konusunda geçerliliği ve güvenilirliği sağlanmış bir başarı testi geliştirme çalışması. Yüzüncü Yıl Üniversitesi Ĕ̌itim Fakültesi Dergisi, 8(1), 40-57.

Hasse, C. (2002). Gender diversity in play with physics: The problem of premises for participation in activities. Mind, Culture, and Activity, 9(4), 250-269.

Heller, P., \& Hollabaugh, M. (1992). Teaching problem solving through cooperative grouping. Part 2: Designing problems and structuring groups. American journal of Physics, 60(7), 637-644.

Henetz, P. \& Groutage, H. (1998). Addressing education's gender bias; science vs. language: Is one set of skills more important?; gender bias addressed in education report. The Salt 
Lake Tribune, https://search.proquest.com/docview/288922851?accountid=16382 adresinden alınmıştır.

Hiscock, K. (1993). The effects of context on solving estimation word problems in children. Yayımlanmamış yüksek lisans tezi, Cartelon University, Canada.

İlhan, N., \& Hoşgören, G. (2017). Fen bilimleri dersine yönelik yaşam temelli başarı testi geliştirilmesi: Asit baz konusu. Fen Bilimleri Öğretimi Dergisi, 5(2), 87-110.

Jones, M. G., Howe, A., \& Rua, M. J. (2000). Gender differences in students' experiences, interests, and attitudes toward science and scientists. Science education, 84(2), 180192.

Kaltakçı-Gürel, D. (2017). Bağlam (yaşam) temelli fizik öğretimi uygulamaları ve REACT stratejisi. A.İ. Şen ve A.R. Akdeniz (Ed.), Fizik öğretimi (357-382). Ankara: Pegem Akademi.

Keeves, J. P. and Kotte, D. (1996). Patterns of science achievement - international comparisons. L. H. Parker, L. J. Rennie and B. Fraser (Ed.), Gender, Science and Mathematics - Shortening the Shadow, Boston: Kluwer Academic Press.

Kılıç, E. (2009). Fen ve teknoloji konularını öğrenme, bilgi kalıcılı̆̆l ve tutumda kavram haritası tekniği ve cinsiyet etkilerinin araştırılması. Yayımlanmamış yüksek lisans tezi, Eğitim Bilimleri Enstitüsü, Gazi Üniversitesi, Ankara.

Kubiszyn, T. \& Borich, G. (2003). Educational testing and measurement: Classroom application and practice (7th ed.). Hoboken, NJ: John Wiley \& Sons, Inc.

Liu, M., Hu, W., Jiannong, S., \& Adey, P. (2010). Gender stereotyping and affective attitudes towards science in Chinese secondary school students. International Journal of Science Education, 32(3), 379-395.

McCullough, L. (2004). Gender, context, and physics assessment. Journal of International Women's Studies, 5(4), 20-30. 
YYÜ Ĕ̌itim Fakültesi Dergisi (YYU Journal of Education Faculty), 2018; 15(1):672-697, http://efdergi.yyu.edu.tr

Milli Eğitim Bakanlığı (2016). PISA 2015 Ulusal Raporu. http://pisa.meb.gov.tr/?page_id=22 adresinden alınmıştır.

Milli Eğitim Bakanlığı. (2017). İlköğretim kurumları fen bilimler dersi (3, 4, 5, 6, 7 ve 8.sınıflar) ögretim programı. Ankara: Devlet Kitapları Basım Evi.

Murphy, P. (1990) Gender gap in the National Curriculum. Physics World, 3(1), 11.

Murphy, P., \& Whitelegg, E. (2006). Girls and physics: Continuing barriers to 'belonging'. The Curriculum Journal, 17(3), 281-305.

National Research Council (NRC) (1996). National science education standards. Washington, DC: National Academies Press.

Nentwig, P. M., Demuth, R., Parchmann, I., Ralle, B., \& Gräsel, C. (2007). Chemie im kontext: Situating learning in relevant contexts while systematically developing basic chemical concepts. Journal of Chemical Education, 84(9), 1439-1444.

Organisation for Economic Co-operation and Development (OECD). (2016). PISA 2015 results: Executive summary. Author.

Palmer, D. (1997). The effect of context on students' reasoning about forces. International Journal of Science Education, 19(6), 681-696.

Park, J., \& Lee, L. (2004). Analysing cognitive or non-cognitive factors involved in the process of physics problem-solving in an everyday context. International Journal of Science Education, 26(13), 1577-1595.

Reid, N., \& Skryabina, E. A. (2003). Gender and physics. International Journal of Science Education, 25(4), 509-536.

Rennie, L. J., \& Parker, L. H. (1996). Placing physics problems in real-life context: students' reactions and performance. Australian Science Teachers Journal, 42(1), 55-59. 
Sencar, S. (2001). The effect of gender on different categories of ninth grade students' misconceptions concerning simple electric circuits. Yayımlanmamış yüksek lisans tezi, Ortadoğu Teknik Üniversitesi, Ankara.

Sencar, S. \& Eryılmaz, A. (2004). Factors mediating the effect of gender on ninth-grade Turkish students' misconceptions concerning electric circuits. Journal of Research in Science Education, 4(6), 603-616.

Sözbilir, M. (2014). Nedensel karşılaştırmalı araştırma yöntemi. Mustafa Metin (Ed.). Kuramdan Uygulamaya Eğitimde bilimsel araştırma yöntemleri. Ankara: Pegem Akademi.

Stevens, J. (2009). Applied multivariate statistics for the social sciences (5th ed.), London: Taylor and Francis Group.

Stewart, M. (1998). Gender issues in physics education. Educational Research, 40(3), 283293.

Tekbıyık, A. \& Akdeniz, A. R. (2010). Bağlam temelli ve geleneksel fizik problemlerinin karşılaştırılması üzerine bir inceleme. Necatibey Eğitim Fakültesi Elektronik Fen ve Matematik Ĕ̈itimi Dergisi, 4(1), 123-140.

Tsai, C. Y. \& Huang, T. C. (2017). The relationship between adult self-efficacy and scientific competencies: the moderating effect of gender. International Journal of Science and Mathematics Education, doi:10.1007/s10763-017-9869-4.

Yerdelen-Damar, S., \& Peşman, H. (2013). Relations of gender and socioeconomic status to physics through metacognition and self-efficacy. The Journal of Educational Research, 106(4), 280-289.

Yildırım, U., \& Eryılmaz, A. (1999). Effects of gender, cognitive development and socioeconomic status on physics achievement. Hacettepe Üniversitesi Eğitim Fakültesi Dergisi, 15(15), 121-126. 
Zohar, A., \& Sela, D. (2003). Her physics, his physics: Gender issues in Israeli advanced placement physics classes. International Journal of Science Education, 25(2), 245-268.

\section{Summary}

Problem Statement: Lately, international examinations such as the TIMSS (Trends in International Mathematics and Science Study) and the PISA (Programme for International Student Assessment) have been in operation and countries are taking the opportunity to evaluate their educational activities and taking necessary precaution. Unfortunately, our country has failed to attain the desired success in these exams compared to other countries (MEB, 2016; OECD, 2016). The most important reason for this failure is students' inability to connect science and mathematics subjects to their real life experiences to solve questions in these exams that are related to real life. Therefore, connecting science subjects to everyday life both in teaching and in the assessment process, will bring along the success of these worldclass exams, as well as contributing to the quality of teaching in general and making knowledge meaningful and permanent (Bellocchi, King and Ritchie, 2016; Nentwig, Demuth, Parchmann, Gräsel and Ralle, 2007). It is known that female and male students have different interests and experiences in science. Despite many years of research to close the gap in gender, the gaps in science, technology, engineering and mathematics are still open to investigation by many researchers (Baram-Tsabari and Yarden, 2008, Dresel, Ziegler, Broome and Heller, 1998; Tsai and Huang, 2017). This gap is particularly striking in the field of physics in science (McCullough, 2004; Zohar and Sela, 2003). In this study, the main aim was to compare the 6th, 7th and 8th grade elementary school students' answers to context-based and traditional questions on the topic of light across gender.

Purpose of the Study: The main purpose of the study was to develop tests including contextbased questions (CBQ) and traditional questions to assess comprehension of 6th, 7th, and 8th grade elementary school students and to compare male and female students' answers to the 
CBQ and traditional questions. The research question investigated is: 'Is there any statistically significant mean difference between male and female students' LAT total scores, CBQ scores and traditional questions scores when their previous science course grades are controlled?

Method: This study is a causal comparative research study. The sample of the study is 869 elementary school students in the 6th, 7th, 8th grade levels in 12 different schools in Izmit district of Kocaeli. The sample was selected by stratified sampling method. In this study, The Light Achievement Test (LAT) developed by the researchers as a data collection instrument was administered to the students. Data were analyzed by SPSS 23.0 statistical program. For each class, the total score from the test, the scores from the context-based questions and the scores from the traditional questions were compared across gender using the MANCOVA test. Findings and Discussions: In this study, the MANCOVA test was used to compare the LAT total scores, the CBQ scores and the traditional question scores of male and female students. According to MANCOVA test results, there was no statistically significant difference between male and female students in LAT total scores, CBQ scores and traditional question scores in 6th (Wilks' $\lambda=0.987, F(2,290)=1.966, p=0.142), 7$ th $($ Wilks' $\lambda=0.991, F(2,278)=1.257$, $p=0.286)$ and 8th (Wilks' $\lambda=0.995, F(2,288)=0.732, p=0.482)$ grade levels. It is noteworthy that girls and boys, who are thought to be different in success in many subjects, are not different in terms of success on the topic of light. As in other subjects, it is thought that if the achievement in the physics course is thought to be subject-specific, it will contribute to the literature in the determination of the subjects in which male and female students have equal success.

Conclusions and Recommendations: In this study it is noteworthy that girls and boys, who are thought to be different in success in many subjects, are not different in terms of success in light topic. In previous studies, especially in the field of physics, male students were found to be more successful than female students (Dresel et al., 1998; Yildirim and Ery1lmaz, 1999), and in particular, various actions were taken to close this gap between female and male students 
in physics. However, it is striking that the studies on this subject have generally accumulated in certain physics topics such as electricity and mechanics (Kılıç, 2009; McCullough, 2004; Sencar, 2001; Eryllmaz, 1999), and some other topics in physics have been researched less. Therefore the determination of the topics (such as light topic in this study) in which male and female students have equal success is thought to be contribute to the science literature. From this point of view, it is an important finding that there is no significant difference in the level of answering the questions on the light topic between male and female students in this study. Keywords: Science education, context-based questions, gender, light. 